\title{
Wind Feedback Mediated by Sea Ice in the Nordic Seas ${ }^{\mathscr{O}}$
}

\author{
TAMÁS KOVÁCS ${ }^{\mathrm{a}}$ AND RÜDIGER GERDES \\ Alfred-Wegener-Institut Helmholtz-Zentrum für Polar- und Meeresforschung, Bremerhaven, Germany \\ JOHN MARSHALL \\ Department of Earth, Atmospheric and Planetary Sciences, Massachusetts Institute of Technology, Cambridge
}

(Manuscript received 20 August 2019, in final form 5 May 2020)

\begin{abstract}
Air-sea interactions play a critical role in the climate system. This study investigates wind-induced changes in the ocean surface temperature and sea ice cover feeding back onto the atmospheric circulation. This interaction was modeled in the Nordic seas, using a partial coupling method to constrain the ocean with prescribed wind forcing in an otherwise fully coupled Earth system model. This enabled the evaluation of not only the direct oceanic, but also the indirect atmospheric response to idealized forcing scenarios of perturbed winds over the Nordic seas. The results show that an anticyclonic wind anomaly forcing leads to significant surface cooling in the Greenland Sea mostly due to anomalous drift of sea ice. During winter, the cooling reduces the net surface heat flux to the atmosphere and increases sea level pressure. The pressure gradients result in anomalous geostrophic southerly winds, which locally are comparable both in direction and in velocity to the prescribed forcing anomalies, suggesting a positive feedback.
\end{abstract}

\section{Introduction}

The wind drives sea surface temperature (SST) anomalies through the modification of air-sea heat fluxes associated with large-scale modes of the atmospheric circulation (Cayan 1992; Marshall et al. 2001). The wind stress curl can result in anomalous upwelling, influencing stratification and thus the SST (Furevik and Nilsen 2005). In high latitudes sea ice plays an important role as a mediator of air-sea fluxes (Meneghello et al. 2018).

Because of the strong internal variability, the effects of SST on the atmosphere are generally difficult to diagnose, especially over cooler ocean surfaces in the extratropics (Xie 2004), where these effects are small relative to a strong internal variability of the atmosphere

\footnotetext{
Supplemental information related to this paper is available at the Journals Online website: https://doi.org/10.1175/JCLI-D-190632.s1.

${ }^{\text {a }}$ Current affiliation: MARUM-Center for Marine Environmental Sciences and Faculty of Geosciences, University of Bremen, Bremen, Germany.
}

Corresponding author: Tamás Kovács, tkovacs@marum.de
(Kushnir et al. 2002). For large-scale anomalies, there is a negative correlation between SST and wind speed (Mantua et al. 1997; Okumura et al. 2001), while the correlation is positive on smaller scales: as Small et al. (2008) and Chelton and Xie (2010) review, a mesoscale $(10-1000 \mathrm{~km})$ increase of SST results in higher net heat loss to the air, reducing atmospheric stability in the boundary layer. The resulting enhanced vertical turbulent mixing brings momentum of strong upper-level winds closer to the surface. A number of papers discuss this response along midlatitude western boundary currents with strong SST gradients and large ocean to atmosphere heat flux. Examples are the Kuroshio (Nonaka and Xie 2003; Xu et al. 2010, 2011), the Agulhas Current (O'Neill et al. 2005; Liu et al. 2007; O'Neill et al. 2010), or the Gulf Stream (Park and Cornillon 2002; Park et al. 2006; Song et al. 2006). However, less work has been done with a focus on high latitudes where sea ice also plays an important role (Alexander et al. 2004; Deser et al. 2004; Bader et al. 2011), for example in the Nordic seas.

The Nordic seas are characterized by strong SST gradients between warm Atlantic Water flowing with the Norwegian Current, and cold Arctic Water along the East Greenland Current (Hurdle 1986; Haine et al. 2015). The latter also carries sea ice, exported from the 
Arctic through Fram Strait (Kwok 2009). The Nordic seas are a key region for the global ocean circulation due to deep water formation through convection, driven by strong heat loss to the atmosphere (Rudels and Quadfasel 1991). Wind forcing over the Nordic seas has been found to influence the SST (Furevik 2000), sea ice extent (Vinje 2001), oceanic circulation (Furevik and Nilsen 2005), and convection (Gerdes et al. 2005). Sea ice change in turn can affect the local atmosphere through modifying the stability of the boundary layer (Wu et al. 2004). In fact, the atmospheric response to oceanic heat flux anomalies in the Nordic seas is strongest in the marginal ice zone (Schlichtholz 2013). A recent study using perturbed wind stress forcing in the Nordic seas found a robust response in water circulation, sea ice, and heat loss to the atmosphere across a suite of model simulations (Muilwijk et al. 2019). However, their forced ocean sea ice models could by construction not reproduce feedbacks that involve wind-driven SST, sea ice, and geostrophic wind anomalies, although observations do suggest such a feedback driven by sea ice changes in the Greenland Sea (Deser et al. 2000).

Our focus is therefore the wind feedback in the Nordic seas region. We use partially coupled model simulations to estimate the indirect response in atmospheric circulation to prescribed idealized wind forcing scenarios, mediated by sea ice and SST. We construct these scenarios following the suggestion of Marshall et al. (2017), presented within the framework of the Forum for Arctic Modeling and Observational Synthesis (FAMOS), an international effort fostering the synthesis of model results and observations with the aim of improving model performance and enhancing understanding of physical processes regulating the Arctic marine environment (Proshutinsky et al. 2020). Our findings here are built on the results of oceanic response to the same forcing scenarios discussed as part of a model intercomparison (Muilwijk et al. 2019), but here we also evaluate the feedback of that response on the wind field.

\section{Methods}

We performed our experiments with the Max Planck Institute Earth System Model (MPI-ESM). It consists of coupled model components simulating the global ocean and atmosphere (Giorgetta et al. 2013). The MPI-ESM has been used to study Arctic sea ice variability (Notz et al. 2013) and predictability (Tietsche et al. 2013), as well as to investigate the covariability of sea ice and atmospheric circulation in the Barents Sea region (Koenigk et al. 2009). We used the lower-resolution version of the MPI-ESM, which produces very similar atmospheric mean state and variability as the higher-resolution version but simulates oceanic processes in the Nordic seas even better, due to the horizontal grid design of the ocean component that allows for a better representation of this region (Jungclaus et al. 2013).

The ocean component in MPI-ESM is called MPI$\mathrm{OM}$, a free-surface ocean-sea ice general circulation model (Marsland et al. 2003). MPI-OM has 40 unevenly spaced vertical levels and uses a curvilinear orthogonal grid with two poles. These are positioned over land in Antarctica and Greenland, providing a horizontal grid spacing of $20-40 \mathrm{~km}$ in the Nordic seas (Jungclaus et al. 2013). This allows a relatively high resolution of SST, which is important for the representation of its impact on surface winds in numerical models (Maloney and Chelton 2006; Song et al. 2009).

The atmospheric component ECHAM6 has a horizontal resolution of approximately $200 \mathrm{~km}$, and 47 vertical levels resolving the atmosphere from the surface up to $0.01 \mathrm{hPa}$ (Stevens et al. 2013). The model components are coupled every $24 \mathrm{~h}$ by cross-boundary fluxes (Giorgetta et al. 2013). The momentum flux between ocean and atmosphere (i.e., the wind stress) is calculated based on the velocity difference between the wind and ocean surface velocity and ice speed, respectively. This provides a better simulation of SST in many regions compared to an only wind-dependent parameterization (Jungclaus et al. 2006). In the original fully coupled configuration, the wind field used to calculate the surface stress is that calculated by ECHAM6; however, here we used a partially coupled configuration with prescribed winds forcing ocean and sea ice. This has been introduced by Thoma et al. (2015) as the Modini method.

The Modini method (Thoma et al. 2015) allows the ocean component MPI-OM to be driven by wind stress based on a prescribed wind field. Apart from the inconsistent momentum coupling, the consistency of heat and energy exchanges are maintained with ECHAM6, which still computes its own wind field according to the fully coupled dynamics. The Modini method was originally designed to spin up and initialize a coupled climate model for decadal prediction. Beyond this purpose, Modini can also be used as an experimental tool to simulate the indirect response of atmospheric circulation to a prescribed wind forcing in a self-consistent way, since the rest of the coupling remains the same as in the original configuration. Thoma et al. (2015) demonstrated the improved skill of Modini-MPI-ESM in simulating both oceanic and atmospheric features associated with the internal variability of the climate.

Our model simulations were based on a fully coupled MPI-ESM run that used the same setup and greenhouse gas forcing as the historical CMIP5 scenario until 2005, and the RCP4.5 emission scenario afterward. The control run of our experiment, a partially coupled run, was restarted from that fully coupled run in 1979 . The source 
(a) CTRL

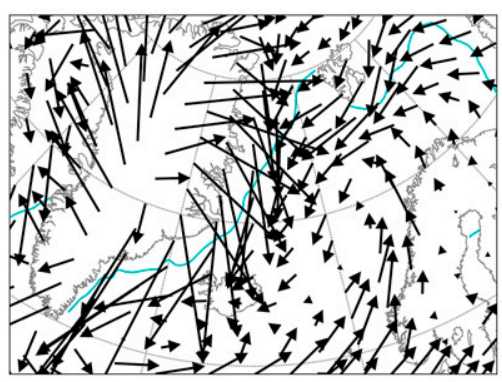

Surface wind climatology $[\overrightarrow{\mathrm{m} / \mathrm{s}}]$ (b) GS+

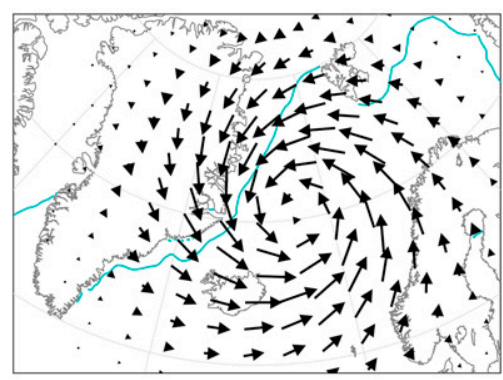

Wind forcing anomaly $[\overrightarrow{\mathrm{m} / \mathrm{s}}]$ (c) GS-

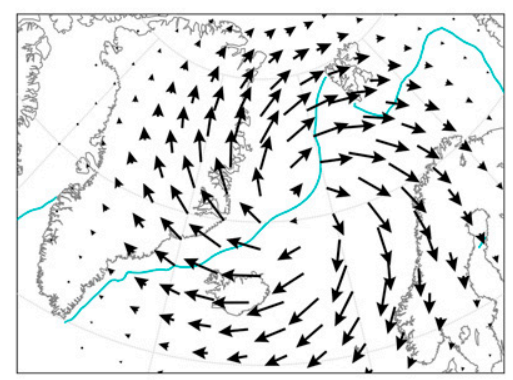

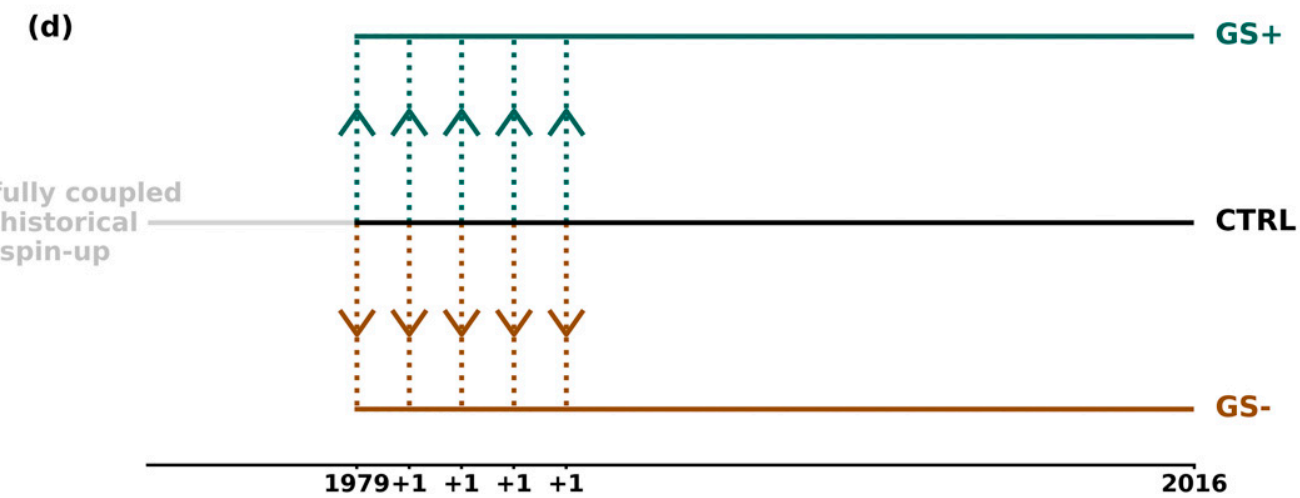

FIG. 1. (a) Time mean of applied wind forcing over the Nordic seas in the control run and (b) the GS + and (c) GS - scenarios' step change in forcing. The blue contour indicates the sea ice edge (contours of sea ice area fraction $=0.15$ ) averaged over the last 15 years of model integration (20-34 years after the step change in forcing). (d) Experiment design, step change in the winds, and ensemble generation.

of external wind data for computing the surface stress was the National Centers for Environmental Protection Climate Forecast System Reanalysis (NCEP CFSR; Saha et al.2010). We applied the variability of its 6-hourly wind series as anomalies to the wind climatology of the fully coupled model (Fig. 1a). Prescribing such an anomaly forcing drives the model system closer to the observed climate while minimizing the influence on its energy balance (Thoma et al. 2015).

We then repeated the same run with perturbed forcing (i.e., a step change in wind) following Marshall et al. (2017). They constructed forcing scenarios of nearsurface geostrophic winds associated with a sea level pressure anomaly of $4 \mathrm{hPa}$, with a radius of influence on the order of $1000 \mathrm{~km}$. These idealized anomalies, centered over the Greenland Sea, represent a cyclonic (GS+; Fig. 1b) and an anticyclonic (GS-; Fig. 1c) perturbation of the circulation over the Nordic seas. The GS + and GS - experiments cover the same time period as the control run (1979-2016). To assess the robustness of the response, we created an ensemble of five members for both scenarios by lagged introduction of the forcing anomalies. We introduced the step change in 1979 for the first member, and delayed it an additional year for each subsequent member (Fig. 1d).

In this study we analyzed winter (November-April) mean model results. Although generally the $10-\mathrm{m}$ wind response to SST changes shows little seasonal variability (O'Neill et al. 2012), the atmospheric surface energy flux response to polar ice change is largest in winter (Deser et al. 2015). In the Nordic seas region the tropospheric response is strongest in winter to the ocean forcing in the summer before (Schlichtholz 2014), and in the BarentsKara Seas the sea ice response to the same forcing perturbations as applied here also occurs mainly during winter (Muilwijk et al. 2019).

\section{Ocean response to wind forcing anomalies}

The applied wind forcing scenarios communicate an anomalous momentum transfer to the ocean. The response of Nordic seas area-mean kinetic energy is rather symmetric in the two scenarios, as illustrated in Fig. 2a, where the solid lines show the surface anomalies, and the dashed lines show the changes at 200-m depth. The changes exceed the interseasonal variability in 


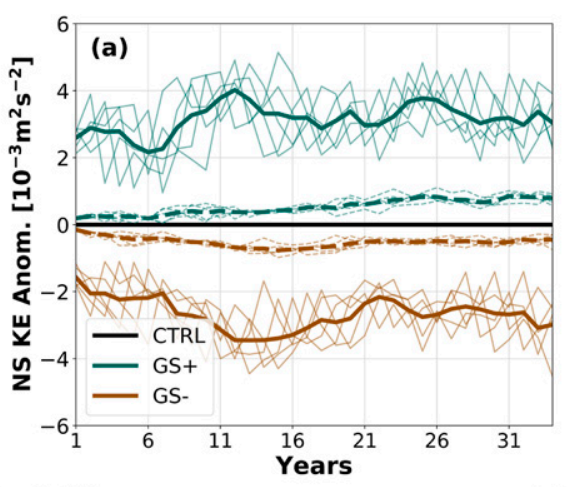

(c) CTRL

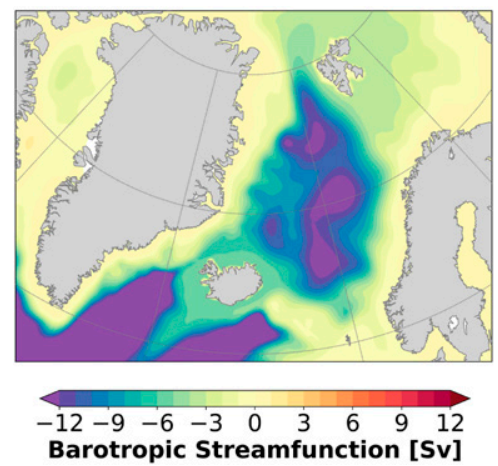

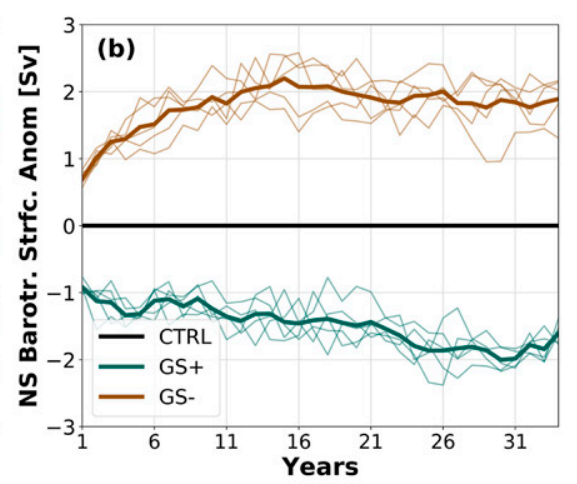

(d) GS+
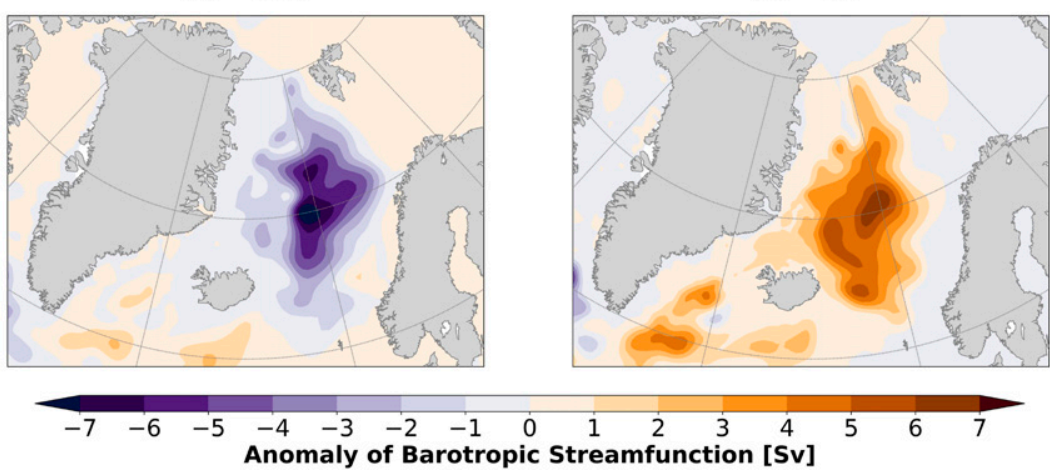

FIG. 2. Time series of response anomaly (relative to the control run) in winter (November-April) Nordic seas area-mean (a) ocean kinetic energy (solid lines: at the surface; dashed lines: at 200-m depth) and (b) horizontal barotropic streamfunction (thick lines are ensemble means; thin lines show results of individual ensemble members). (c) Control run result and (d) GS + and (e) GS - anomalies of winter barotropic streamfunction as spatial distributions averaged over the last 15 years of model integration (20-34 years after step change in forcing; control run climatology, and ensemble-mean anomalies relative to the control run).

the control run near the surface and are more than 3 times larger at 200-m depth (the time series of absolute values are presented in Figs. S1a,b in the online supplemental material). This significantly modifies the strength of the local barotropic circulation. The anomalies of the Nordic seas area-mean barotropic streamfunction reach about -2.0 and $+2.2 \mathrm{~Sv}\left(1 \mathrm{~Sv}=10^{6} \mathrm{~m}^{3} \mathrm{~s}^{-1}\right)$ in the GS+ scenario and in the GS- scenario, respectively (Fig. 2b; see absolute values in Fig. S1c). The barotropic flow in the Nordic seas is characterized by a cyclonic circulation in the control simulation (Fig. 2c). Its strength reaches $13 \mathrm{~Sv}$, which is similar to estimates based on profiling float observations (Voet et al. 2010). The applied cyclonic (anticyclonic) wind forcing perturbation causes a spinup (spindown) of this cyclonic circulation (Figs. 2d,e), in agreement with the barotropic model of Isachsen et al. (2003). The extent of this change in Modini-MPI-ESM is within the range of the multimodel ensemble of Muilwijk et al. (2019).

Perturbations of the wind field also affect sea ice cover. The mean state of regional winter sea ice concentration in the control experiment (Fig. 3a) is characterized by a high concentration north of Greenland and in the western side of Fram Strait (over 0.9). Most of the Nordic seas is ice-free; sea ice is present only along the eastern coast of Greenland, covering a much larger area with higher (over 0.9) mean extent in the Greenland Sea, and gradually becoming confined to the coast farther south. Although the model performs generally well in comparison with observations, it is known to underestimate the extent of sea ice in the Greenland Sea (Notz et al. 2013). In the cyclonic GS + scenario the ice concentration is lower (by up to 0.5 ) along the eastern coast of Greenland (Fig. 3b), while the response in the anticyclonic GS - scenario is an even larger (up to above 0.7; Fig. 3c) high concentration anomaly.

The sea ice concentration anomalies are primarily due to wind-driven dynamic changes, and have important implications on the heat budget of surface waters. As shown in Fig. 3d, sea ice in the Greenland Sea is transported southward in the control simulation, following the pathway of Arctic ice export through Fram Strait. The wind perturbations displace the pathway of this export: in the GS + scenario (Fig. 3e), enhanced cyclonic winds push the ice closer to Greenland, decreasing the strength of southward ice transport everywhere except 
(a) CTRL

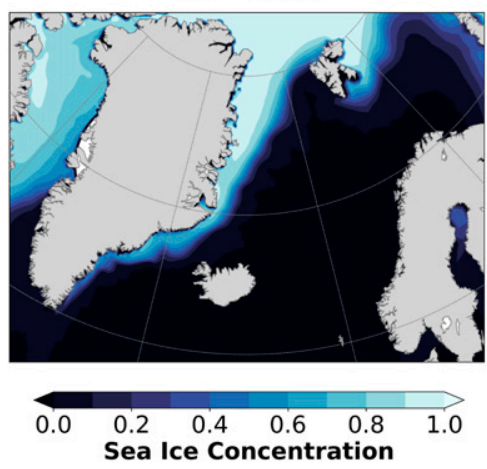

(d) CTRL

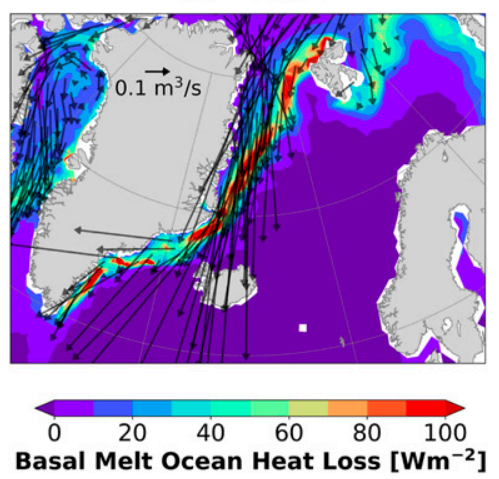

(b) GS+

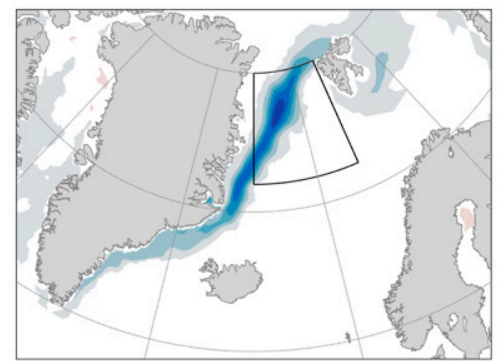

$\begin{array}{lllllllllll}-0.7-0.6-0.5-0.4-0.3-0.2 & -0.1 & 0.0 & 0.1 & 0.2 & 0.3 & 0.4 & 0.5 & 0.6 & 0.7\end{array}$

(e) GS+

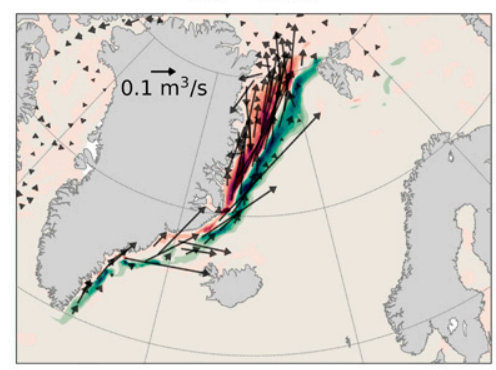

(f) GS-

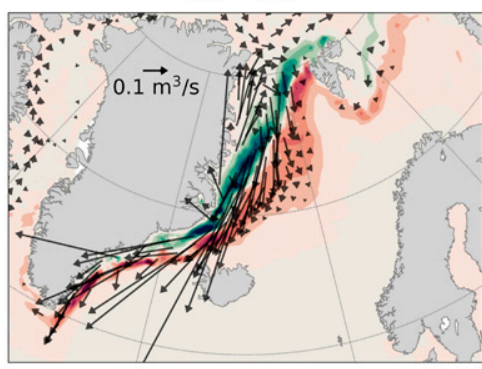

$$
-80
$$

(c) GS-
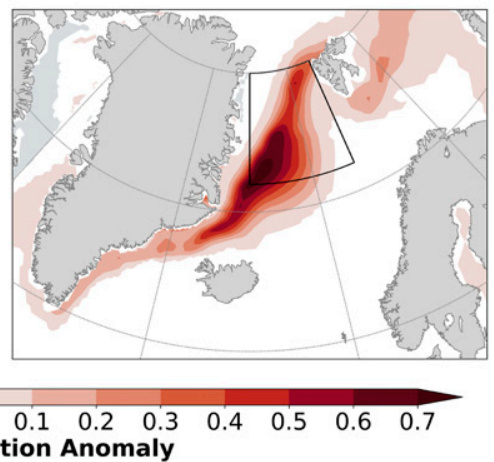

Basal Melt Ocean Heat Loss Anomaly [W $\left.\mathbf{W m}^{-2}\right]$

FIG. 3. (a) Winter (November-April) mean climatology of sea ice concentration in the control run and (b) GS + and (c) GS - mean anomalies relative to the mean control climatology. The Greenland Sea domain is highlighted in black. (d) Winter (November-April) mean climatology of sea ice volume transport (arrows) and ocean heat loss to basal melt (colors) in the control run and (e) GS+ and (f) GS - mean anomalies relative to the mean control climatology. In (b), (c), (e), and (f) anomalies are averaged over the last 15 years of model integration (20-34 years after step change in forcing).

directly along the coast. The retreating ice edge means that much less heat is lost to basal melt in the surface layers of the open Greenland Sea, and the melting can increase along the western boundary where it was not significant before, further enhancing the loss of ice. The anticyclonic winds in the GS - scenario (Fig. 3f) displace the main pathway of ice export much farther east, covering previously open waters with ice, but also reducing the southward transport close to the coast. The highest basal melt rate is also shifted eastward, illustrated by the reduced heat loss of the waters along the original ice edge, and the increased heat loss of newly ice-covered waters in the open Greenland Sea.

The changes in heat loss of surface waters due to basal melt lead to significant SST anomalies in the Greenland Sea. According to Fig. 4, the time development of the SST response (solid lines) is tightly linked to the asymmetric response of sea ice extent (dashed lines). The Greenland Sea area-mean SST response reaches between $+0.6^{\circ}$ and $+1.2^{\circ} \mathrm{C}$ after 3 years in the GS + scenario, and between $-2.2^{\circ}$ and $-2.6^{\circ} \mathrm{C}$ after about 15 years in the
GS - scenario (for absolute values see Fig. S1e). Compared to the mean SST of the control simulation (Fig. 5a), the spatial pattern of the response in the Greenland Sea (Figs. 5b,c) closely follows the pattern of ice concentration anomalies and the heat loss anomalies they induce (Fig. 3).

In addition to the asymmetric but opposing SST anomalies in the Greenland Sea, the Norwegian Sea is cooler in both scenarios (Figs. 5b,c). In the anticyclonic GS - scenario this is explained by a significant reduction of Atlantic Water inflow across the Iceland-Scotland Channel, which brings much less heat northward (see Fig. S1f). However, there is no such significant change in the lateral heat flux in the GS+ scenario. In that case, the SST response is the combined effect of both horizontal and vertical circulation anomalies. The cyclonic wind anomalies of this scenario drive a stronger recirculation of cold Arctic water from the East Greenland Current along the East Iceland Current. Moreover, this area corresponds to the largest anomalies in wind stress curl due to the placement of the wind forcing anomalies, 


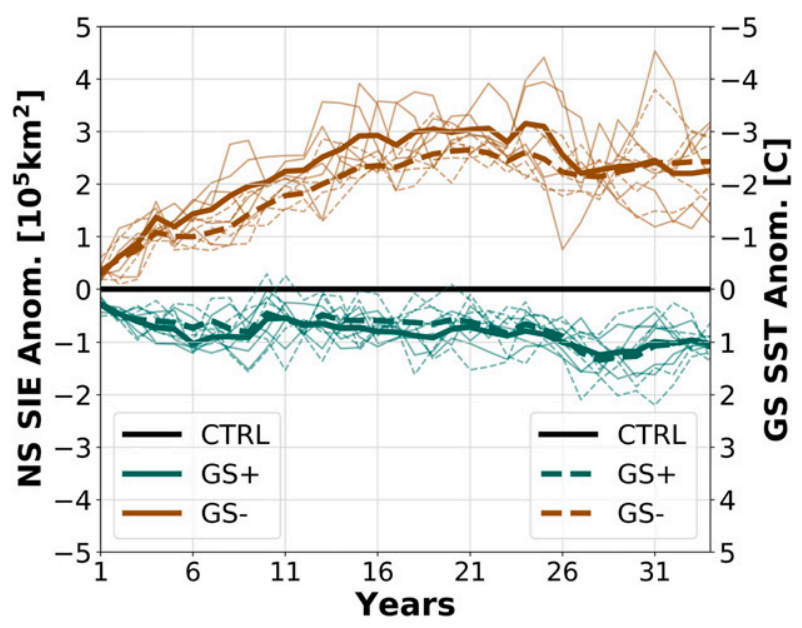

FIG. 4. Time series of response anomaly (relative to the control run) in winter (November-April) Nordic seas area-mean sea ice extent (solid lines) and Greenland Sea area-mean sea surface temperature (dashed lines). Thick lines are ensemble means; thin lines show results of individual ensemble members.

so here the vertical motion also plays a role. The cyclonic wind anomaly of the GS+ scenario induces an anomalous upwelling that brings cooler water from below close to the surface (see vertical profiles of temperature and upwelling in supplemental Fig. S2).

Sea ice cover and SST have a strong impact on the ocean to air cross-boundary heat flux, as can be seen in the control simulation in Fig. 5d: the model considers the net heat flux to be negligible where sea ice insulates the water from air, and to be high (up to $300 \mathrm{~W} \mathrm{~m}^{-2}$ ) in regions with cold air and warmer SST, such as southwest from Svalbard. The applied wind perturbations significantly modify these fluxes where large surface anomalies are present (cf. the response in Figs. 5e,f to the SST anomalies in Figs. 5b,c) and therefore have an indirect effect on the atmosphere.

\section{Indirect atmospheric response}

The SST anomalies are tightly linked to changes in the net heat flux to the atmosphere. In both scenarios, their time series show a significant correlation (with $99 \%$ confidence) almost everywhere, where the SST anomaly is larger than $1.0^{\circ} \mathrm{C}$, and the rate of their response typically reaches around $20-30 \mathrm{~W} \mathrm{~m}^{-2}{ }^{\circ} \mathrm{C}^{-1}$ and up to $40-50 \mathrm{~W} \mathrm{~m}^{-2}{ }^{\circ} \mathrm{C}^{-1}$ along the displaced sea ice edge (see Figs. S3a,b). Overall, the ocean-atmosphere net heat flux increases by up to around $140 \mathrm{~W} \mathrm{~m}^{-2}$ along the Greenland Sea marginal ice zone in the GS+ scenario, and decreases by as much as $-180 \mathrm{~W} \mathrm{~m}^{-2}$ in newly icecovered regions in the GS- scenario (Fig. 5). These anomalous heat fluxes affect the stability of the atmospheric marine boundary layer, illustrated by the changes in sea level pressure.

MPI-ESM simulates the mean climatology of atmospheric sea level pressure (SLP) in the Nordic seas region with only small biases (Stevens et al. 2013). In comparison with observations, winter SLP computed by the fully coupled model is about $4 \mathrm{hPa}$ higher around Svalbard, and about $2 \mathrm{hPa}$ lower over Great Britain. For the geostrophic circulation of air, it means a positive bias of easterly winds over the Nordic seas in winter. The spatial distribution of these biases are similar in our partially coupled control run, since the prescribed wind forcing retains the mean climatology of the fully coupled system, and applies only the variability of the NCEP CFSR wind series onto that.

Due to the effect of the prescribed wind anomaly forcing, the interseasonal variability of SLP (and thus the geostrophic winds) in our control run closely resembles that of the NCEP CFSR series. The temporal standard deviation of winter SLP series is the lowest (lower than $2.9 \mathrm{hPa}$ ) over the northern half of the Nordic seas, and is the highest (higher than $3.3 \mathrm{hPa}$ ) around Iceland (Fig. 6a). The SLP anomaly of $4 \mathrm{hPa}$, with which the wind perturbation in our idealized forcing scenarios is associated, is thus comparable to the local temporal standard deviation of winter means of modeled SLP.

The strength and spatial distribution of the SLP response (Figs. $6 b, c$ ) follows that of the heat flux and the SST (cf. Figs. 5b,c,e,f). In the cyclonic GS + scenario the response is a pressure dipole between the Greenland and Norwegian Sea: there is a low pressure anomaly of about $-0.6 \mathrm{hPa}$ over the Greenland Sea, and a high pressure anomaly of about $+1.2 \mathrm{hPa}$ over the Norwegian Sea. In the anticyclonic GS- scenario, the Nordic seas SLP response is dominated by a positive anomaly of about $+1.1 \mathrm{hPa}$ centered over the Greenland Sea.

Figures $6 \mathrm{e}$ and $6 \mathrm{f}$ present the $10-\mathrm{m}$ wind response to the prescribed wind forcing scenarios. In the cyclonic GS + case there is a pattern of anticyclonic winds over the central Nordic seas, and the strength of this anomaly reaches $0.9 \mathrm{~m} \mathrm{~s}^{-1}$ over the Greenland Sea and $0.7 \mathrm{~m} \mathrm{~s}^{-1}$ over the Norwegian Sea. There is a weaker response in a few other areas-namely southwestern winds across the Barents Sea Opening, and southerly winds across the eastern side and northerly winds across the western side of Fram Strait-but the strength of these is below $0.4 \mathrm{~m} \mathrm{~s}^{-1}$, hardly distinguishable from noise. In the anticyclonic GS - scenario, there is a strong southerly wind over most of the Greenland Sea that reaches a strength of $1.5 \mathrm{~m} \mathrm{~s}^{-1}$. This response extends farther north into the Arctic across Fram Strait. A weaker anticyclonic circulation pattern over the central Nordic seas features winds of up to approximately $0.5 \mathrm{~m} \mathrm{~s}^{-1}$. 
(a) CTRL

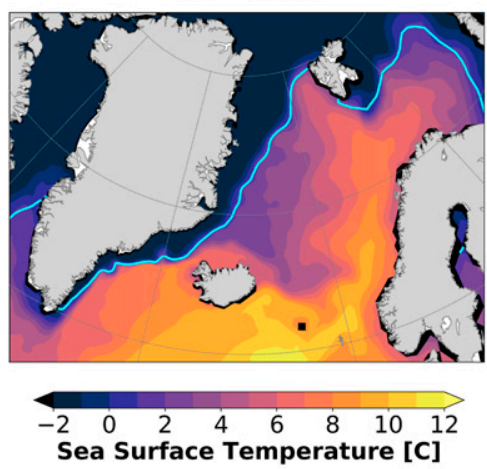

(d) CTRL

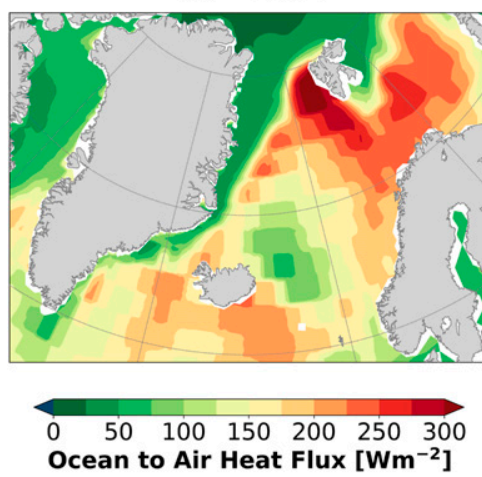

(b) GS+

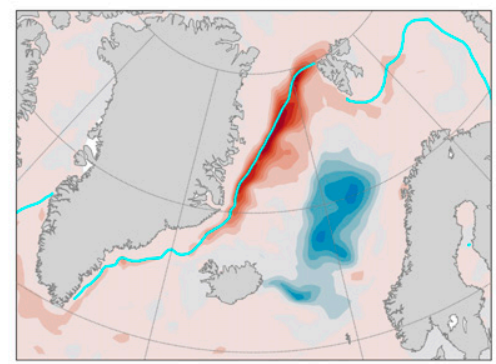

(c) GS-

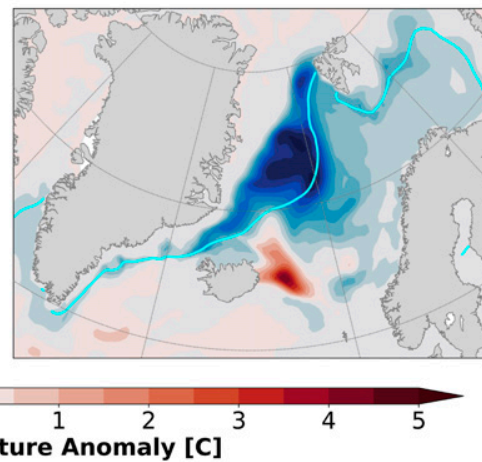

(f) GS-
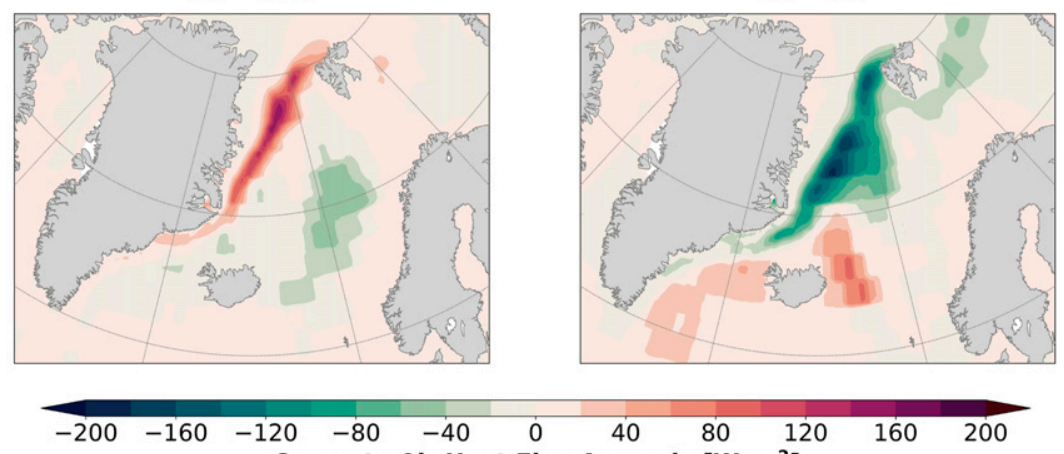

FIG. 5. (a) Winter (November-April) mean climatology of sea surface temperature in the control run and (b) GS + and (c) GS - mean anomalies relative to the mean control climatology, with the sea ice edge (contour of area fraction $=0.15$ ) in light blue. (d) Winter (November-April) mean climatology of ocean heat flux to the atmosphere in the control run and (e) GS + and (f) GS - mean anomalies relative to the mean control climatology. In (b), (c), (e), and (f) anomalies are averaged over the last 15 years of model integration (20-34 years after step change in forcing).

The color shading in Figs. 6e and 6f indicates the strength of the feedback as the rate of the wind speed between the response and the prescribed forcing anomaly, where their direction does not differ more than $60^{\circ}$. According to Fig. 6e, there is no significant feedback in the GS+ scenario, but in the GS - scenario (Fig. 6f) the response is similar to the forcing over much of the Nordic seas, especially over the western Greenland Sea.

\section{The wind feedback}

Overall, the temperature anomalies are the strongest in the Greenland Sea, close to the surface. Ocean-sea ice models forced with the same wind perturbations show significant changes in lateral heat transport across sections bordering the Nordic seas (Muilwijk et al. 2019), but our results do not. Still, the spatial distribution of our SST response is very similar to what Muilwijk et al. (2019) present. This implies that the Greenland Sea SST response is created within the region due to wind forcing, and is not advected there from outside the
Nordic seas, as has been suggested by previous studies based on observations (Furevik 2000) and model experiments (Kauker et al. 2005).

In this locally created SST response, sea ice plays a key role. We find that its extent is negatively correlated with the strength of the cyclonic winds over the Nordic seas, which is related to the local storm intensity and also to the North Atlantic Oscillation (Sorteberg et al. 2005). This agrees with previous studies that found a negative correlation between Greenland Sea ice extent and the NAO (Vinje 2001; Visbeck et al. 2003; Macias Fauria et al. 2010). Although here we perturbed the wind field only near one center of action associated with the NAO, we find the same response in sea ice. This is because the key mechanism, the displacement of the Arctic sea ice export pathway by Ekman drift, is driven by anomalous local winds, whose strength is connected to the NAO, as can be seen in observations as well (Germe et al. 2011).

Our results show that changes in SST and sea ice cover significantly modify the net ocean heat flux to the atmosphere, influencing the stability of the marine boundary 
(a) CTRL

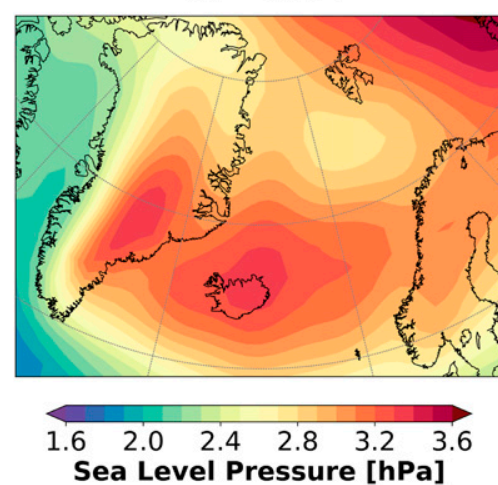

(d) CTRL

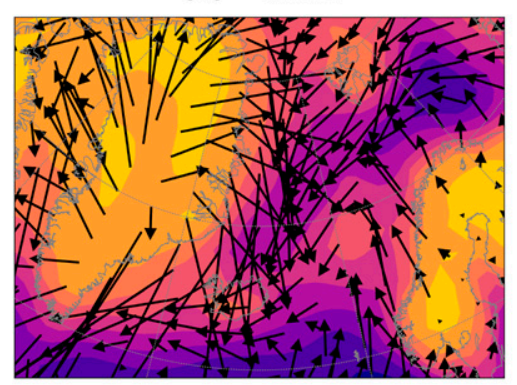

$\begin{array}{lllll}0.0 & 0.4 & 0.8 & 1.2 & 1.6 \rightarrow 2.0\end{array}$ $10 \mathrm{~m}$ Wind Speed $[\mathrm{m} / \mathrm{s}]$

(b) GS+

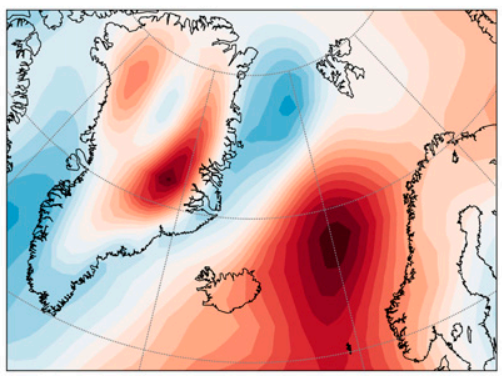

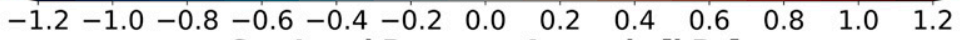
Sea Level Pressure Anomaly [hPa]

(e) GS+

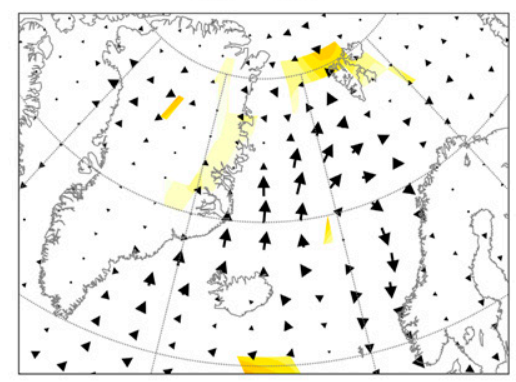

(c) GS-

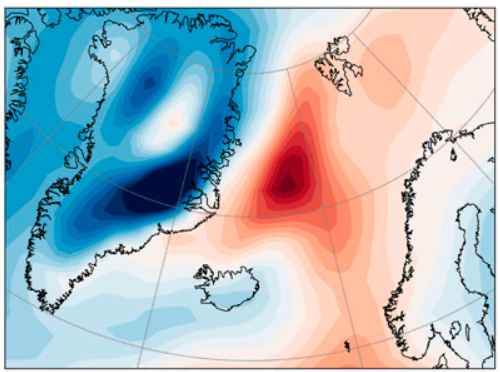

(f) GS-

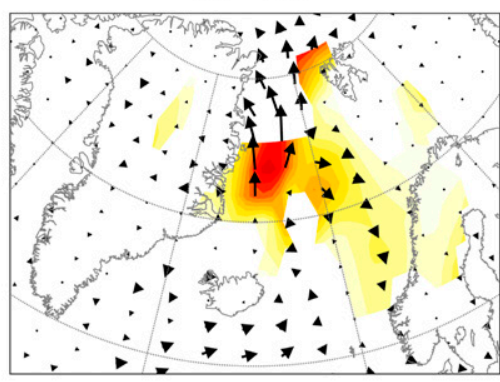

1.0

and Feedback Rate

FIG. 6. (a) Temporal standard deviation of winter (November-April) means of atmospheric sea level pressure in the control run and (b) GS + and (c) GS - mean anomalies relative to the mean control climatology. (d) Temporal standard deviation of winter (NovemberApril) means of 10-m wind speed (colors) and mean wind climatology (arrows) in the control run. (e) GS + and (f) GS - mean anomalies of winter (November-April) 10-m wind relative to the control run (arrows) and the strength of the feedback as the rate of the wind speed between the response anomalies and the prescribed forcing anomaly (see Fig. 1), where their direction does not differ more than $60^{\circ}$. In (b), (c), (e), and (f) anomalies are averaged over the last 15 years of model integration (20-34 years after step change in forcing).

layer. Sea ice plays a particularly important role, lowering SST due to its melting, but also insulating ocean water from the air. These processes reduce both the latent and sensible heat flux to the atmosphere, leading to generally more stable air over sea ice. Observational evidence points to the importance of this effect in the Greenland Sea (Deser et al. 2000; Wu et al. 2004), where the response is the strongest in our simulations. Previous modeling studies also show an atmospheric response to changes in sea ice cover, with near-surface cooling and increased SLP where sea ice expanded, and the reverse where the ice receded (Royer et al. 1990; Alexander et al. 2004; Koenigk et al. 2009).

The response of atmospheric SLP follows the SST and sea ice anomalies. The response to the Greenland Sea SST changes translates to approximately $-0.2 \mathrm{hPa}^{\circ} \mathrm{C}^{-1}$ in both scenarios (see Figs. S3c,d), indicating a high sensitivity of the atmospheric circulation to the lower boundary conditions. The response to the Norwegian
Sea SST changes reaches $-0.6 \mathrm{hPa}^{\circ} \mathrm{C}^{-1}$ in the $\mathrm{GS}+$ scenario. The resulting local SLP anomalies translate to $20 \%-40 \%$ of the corresponding temporal standard deviation in the control run (cf. Figs. 6b,c and Fig. 6a). The SLP response in the GS- scenario is located very close to the center of the forcing perturbation, and is $28 \%$ of the $4 \mathrm{hPa}$ anomaly with which its wind forcing anomaly field is associated.

The response in near-surface winds is related to the gradient of the SLP anomalies. Due to the localized patterns of the SLP response, its gradients are relatively large, partly explaining the high sensitivity mentioned above. This means that the response in geostrophic winds is also quite large, especially if we compare it to the original wind perturbation of our idealized forcing scenarios. The wind response in the GS- scenario is particularly interesting, as it suggests a strong positive feedback: the southerly winds over the Greenland Sea (up to $1.5 \mathrm{~m} \mathrm{~s}^{-1}$; Fig. 6f) are not only similar in direction 
and comparable to the local strength of the applied forcing anomaly (1.3-1.5 $\mathrm{m} \mathrm{s}^{-1}$; Fig. 1c), but are also stronger than the local interseasonal variability in the control simulation $\left(0.8-1.4 \mathrm{~m} \mathrm{~s}^{-1}\right.$; Fig. $\left.6 \mathrm{~d}\right)$.

\section{Concluding discussion}

We have simulated the influence of wind-induced winter ice and SST anomalies on the atmosphere in the Nordic seas region with a partially coupled model, and found a positive wind feedback effect. The model configuration we have used enabled us to evaluate not only the oceanic response to prescribed wind forcing scenarios, but also the self-consistent indirect response in the coupled atmospheric model component.

Our model simulations show that changes in the strength of the cyclonic winds over the Nordic seas cause significant anomalies in sea ice cover and SST especially in the Greenland Sea. Cyclonic (anticyclonic) wind forcing anomalies push the ice closer to (farther east from) Greenland, reducing (increasing) the ice extent and warming (cooling) the sea surface in the Greenland Sea. This leads to anomalous ocean-air heat fluxes that modify the stability of the atmospheric boundary layer: SLP decreases (increases) over warmer and ice-free (cooler and ice-covered) water. In case of a cyclonic forcing, the response of geostrophic winds corresponding to the gradients of these local SLP anomalies is weak and does not resemble the prescribed forcing. But in the anticyclonic forcing scenario, there is a stronger response of southerly winds over the Greenland Sea, comparable both in terms of velocity and direction to the prescribed forcing wind field. This is illustrated in Fig. 7. These southerly winds, mainly driven by sea ice displaced by Ekman drift due to local southerly winds, suggest a positive feedback.

The oceanic and the atmospheric responses are both stronger in the anticyclonic GS- scenario. This asymmetry might be partly due to biases in simulated sea ice cover. The model is known to overestimate the ice concentration in the central Arctic, and to generate thinner ice and lower concentration than observed around Greenland (Jungclaus et al. 2006). This is particularly true for the Greenland Sea (Notz et al. 2013), where the ice edge thus has more potential to extend east than to recede farther west. This means that the asymmetry of the response presented here might not be found in other models. However, there is observational evidence that the Greenland Sea ice extent responds stronger to negative NAO (locally similar to GS-) forcing than to positive (Germe et al. 2011), and the atmospheric response to SST and ice-induced heating anomalies also scales nonlinearly with respect to the
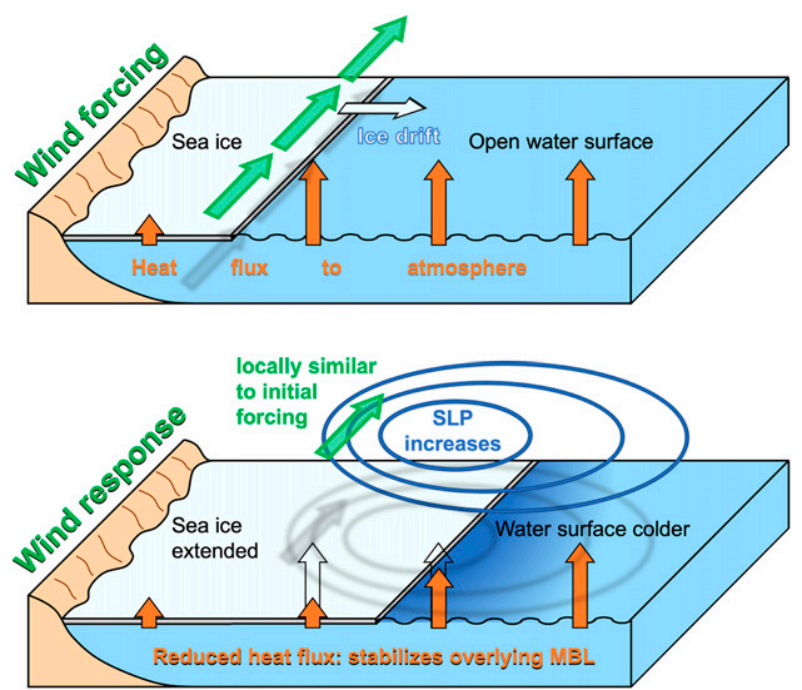

FIG. 7. Schematic of the wind feedback in the anticyclonic GS - scenario. (top) Southerly winds along the ice edge push the ice eastward, increasing its extent. (bottom) In newly icecovered areas and over a colder water surface the ocean-air heat fluxes reduce, leading to the stabilization of the overlying atmospheric marine boundary layer (MBL). The gradients of the corresponding increase of atmospheric sea level pressure (SLP) result in geostrophic winds that are locally comparable in terms of both velocity and direction to the forcing wind field. This suggests a positive feedback.

polarity of the forcing in an earlier model study (Deser et al. 2004).

Although the SST anomalies are similarly strong in the summer months, the respective atmospheric response is much weaker (see Fig. S4). This is consistent with previous studies that found the atmospheric response to sea surface forcing to be strongest in winter (e.g., Deser et al. 2010; Schlichtholz 2014; Muilwijk et al. 2019).

The wind feedback in the anticyclonic scenario is rather strong, and the winter response over the Greenland Sea is robust across the ensemble (see Fig. S5). This response is as strong as the velocity of the prescribed wind field in our model experiments, which is likely still an underestimation, since the linear relation between SST and surface wind speed in models is generally weaker by a factor of 2-4 in comparison with observations (Chelton and Xie 2010). Also, it should be noted that the partial coupling suppresses part of the feedback effect. While the atmospheric model component responds to the oceanic changes, the ocean model component does not receive information of the response in the wind field-for the sake of clarity of the experiment its wind forcing is prescribed and the air-ocean momentum forcing is decoupled.

The change of near-surface winds is not the only response in the atmosphere to oceanic forcing. In this 
study we focused on the wind response, but changes in sea ice certainly affect other important processes, for example cloud formation and precipitation (Royer et al. 1990; Koenigk et al. 2009). How other atmospheric parameters respond to forcing scenarios such as in our experiments we consider to be an interesting question for future studies.

In addition to the mentioned atmospheric processes, larger-scale oceanic processes like the advective heat transport need to be considered. Changes in the marginal ice zone associated with such transport likely induce smallscale SLP structures and enhanced sensitivity. However, with the current experimental design and diagnostics we could not isolate further feedbacks. A number of ocean models forced with the same wind perturbations that we applied here show a significant change in poleward heat transport along the pathway of Atlantic Water across the Nordic seas, and a clear response in Arctic sea ice extent (Muilwijk et al. 2019). Our model configuration enabled us to evaluate to atmospheric response as well, but we had to limit our focus to the Nordic seas, as the oceanic response in our model was unclear outside of its region, and inconsistent with the findings of Muilwijk et al. (2019). Similar future experiments with targeted perturbations could provide useful insights for other regions as well, for example in the Barents Sea, where the wind feedback might even play a role on a hemispheric level, but its dominance over a longer time scale is uncertain (Smedsrud et al. 2013).

The temporal robustness of the wind feedback in the Greenland Sea is also a question. In this area both oceanic and atmospheric parameters exhibit high variability, and on different time scales. The local winds driving the sea ice changes in our simulations are connected to different phases of the NAO, and thus show large long-term variability (Germe et al. 2011). Therefore, although our perturbation and its oceanic response can be considered realistic, the response in the atmosphere might be masked by its large variability, since in the Nordic seas the SST-forced component is less than $20 \%$ of the total SLP variance (Kushnir et al. 2002). The air-ocean interactions are also not necessarily robust in time: the relationship between Greenland Sea ice extent and the NAO is nonstationary over a period of several hundred years (Macias Fauria et al. 2010). Recent observations also show a strong influence of local SST on the NAO phase before the late 1970s, but not afterward (Nakamura 2013), suggesting that perhaps other factors with a lowerfrequency variability could influence the relationship.

Nevertheless, our results confirm that there is a potential for a wind feedback in the local air-ocean-ice coupled system, and we assume that this effect could play an important role in the near future. The global trends of temperature increase are amplified in the Arctic largely due to the role of diminishing sea ice (Screen and Simmonds 2010), and the existing ice cover has also become thinner and more responsive to wind forcing (Kwok et al. 2013). Although no significant change has yet been observed in the volume of sea ice exported from the Arctic through Fram Strait, it is expected to reduce drastically during the twenty-first century (Haine et al. 2015). This certainly means thinner ice in the Greenland Sea, but also more mobile ice. The results we discussed here suggest that a reduction in cyclonic winds could delay the westward retreat of the ice edge and the reduction of its extent, while the absence of a wind feedback contributing to its eastward extension could mean an even faster retreat in case of increased cyclonicity.

Acknowledgments. TK and RG are supported by the cooperative project 03F0729E (RACE II and RACE-NORDATLANTIK Synthesis, Regional Atlantic Circulation and Global Change), funded by the German Federal Ministry for Education and Research (BMBF). TK would like to thank the generous travel support of the Forum for Arctic Modeling and Observational Synthesis (FAMOS) and the National Science Foundation (NSF), and the POLMAR graduate school. RG gratefully acknowledges funding by the Deutsche Forschungsgemeinschaft (DFG, German Research Foundation), Projektnummer 268020496, TRR 172, within the Transregional Collaborative Research Center "ArctiC Amplification: Climate Relevant Atmospheric and SurfaCe Processes, and Feedback Mechanisms". JM would like to thank the NSF Arctic program of the NSF. The authors are grateful to the editor Rong Zhang and three anonymous reviewers for their valuable suggestions that substantially improved the manuscript.

\section{REFERENCES}

Alexander, M. A., U. S. Bhatt, J. E. Walsh, M. S. Timlin, J. S. Miller, and J. D. Scott, 2004: The atmospheric response to realistic Arctic sea ice anomalies in an AGCM during winter. J. Climate, 17, 890-905, https://doi.org/10.1175/ 1520-0442(2004)017<0890:TARTRA > 2.0.CO;2.

Bader, J., M. D. S. Mesquita, K. I. Hodges, N. Keenlyside, S. Østerhus, and M. Miles, 2011: A review on Northern Hemisphere sea-ice, storminess and the North Atlantic Oscillation: Observations and projected changes. Atmos. Res., 101, 809-834, https://doi.org/ 10.1016/j.atmosres.2011.04.007.

Cayan, D. R., 1992: Latent and sensible heat-flux anomalies over the northern oceans: The connection to monthly atmospheric circulation. J. Climate, 5, 354-369, https://doi.org/10.1175/ 1520-0442(1992)005<0354:LASHFA > 2.0.CO;2.

Chelton, D. B., and S.-P. Xie, 2010: Coupled ocean-atmosphere interaction at oceanic mesoscales. Oceanography, 23, 52-69, https://doi.org/10.5670/oceanog.2010.05. 
Deser, C., J. E. Walsh, and M. S. Timlin, 2000: Arctic sea ice variability in the context of recent atmospheric circulation trends. J. Climate, 13, 617-633, https://doi.org/10.1175/1520-0442(2000) 013<0617:ASIVIT >2.0.CO;2.

_ , G. Magnusdottir, R. Saravanan, and A. Phillips, 2004: The effects of North Atlantic SST and sea ice anomalies on the winter circulation in CCM3. Part II: Direct and indirect components of the response. J. Climate, 17, 877-889, https://doi.org/ 10.1175/1520-0442(2004)017<0877:TEONAS > 2.0.CO;2.

$\longrightarrow$, R. Tomas, M. Alexander, and D. Lawrence, 2010: The seasonal atmospheric response to projected Arctic sea ice loss in the late twenty-first century. J. Climate, 23, 333-351, https:// doi.org/10.1175/2009JCLI3053.1.

—,- , and L. Sun, 2015: The role of ocean-atmosphere coupling in the zonal-mean atmospheric response to Arctic sea ice loss. J. Climate, 28, 2168-2186, https://doi.org/10.1175/JCLI-D-14-00325.1.

Furevik, T., 2000: On anomalous sea surface temperatures in the Nordic seas. J. Climate, 13, 1044-1053, https://doi.org/10.1175/ 1520-0442(2000)013<1044:OASSTI >2.0.CO;2.

— , and J. E. Ø. Nilsen, 2005: Large-scale atmospheric circulation variability and its impacts on the Nordic seas ocean climate-A review. The Nordic Seas: An Integrated Perspective, Geophys. Monogr., Vol. 158, Amer. Geophys. Union, https://doi.org/ 10.1029/158GM09.

Gerdes, R., J. Hurka, M. Karcher, F. Kauker, and C. Köberle, 2005: Simulated history of convection in the Greenland and Labrador Seas, 1948-2001. The Nordic Seas: An Integrated Perspective, Geophys. Monogr., Vol. 158, Amer. Geophys. Union, 221-238, https://doi.org/10.1029/158GM15.

Germe, A., M.-N. Houssais, C. Herbaut, and C. Cassou, 2011: Greenland Sea sea ice variability over 1979-2007 and its link to the surface atmosphere. J. Geophys. Res., 116, C10034, https://doi.org/10.1029/2011JC006960.

Giorgetta, M. A., and Coauthors, 2013: Climate and carbon cycle changes from 1850 to 2100 in MPI-ESM simulations for the Coupled Model Intercomparison Project phase 5. J. Adv. Model. Earth Syst., 5, 572-597, https://doi.org/10.1002/jame.20038.

Haine, T. W. N., and Coauthors, 2015: Arctic freshwater export: Status, mechanisms, and prospects. Global Planet. Change, 125, 13-35, https://doi.org/10.1016/j.gloplacha.2014.11.013.

Hurdle, B. G., 1986: The Nordic Seas. Springer-Verlag, 777 pp.

Isachsen, P. E., J. H. LaCasce, C. Mauritzen, and S. Häkkinen, 2003: Wind-driven variability of the large-scale recirculating flow in the Nordic seas and Arctic Ocean. J. Phys. Oceanogr., 33, 2534-2550, https://doi.org/10.1175/15200485(2003)033<2534:WVOTLR>2.0.CO;2.

Jungclaus, J. H., and Coauthors, 2006: Ocean circulation and tropical variability in the coupled model ECHAM5/MPI-OM. J. Climate, 19, 3952-3972, https://doi.org/10.1175/JCLI3827.1. - and Coauthors, 2013: Characteristics of the ocean simulations in the Max Planck Institute Ocean Model (MPIOM) the ocean component of the MPI-Earth system model. J. Adv. Model. Earth Syst., 5, 422-446, https://doi.org/10.1002/jame.20023.

Kauker, F., R. Gerdes, M. Karcher, and C. Köberle, 2005: Impact of North Atlantic current changes on the Nordic seas and the Arctic Ocean. J. Geophys. Res., 110, C12002, https://doi.org/ 10.1029/2004JC002624.

Koenigk, T., U. Mikolajewicz, J. H. Jungclaus, and A. Kroll, 2009: Sea ice in the Barents Sea: Seasonal to interannual variability and climate feedbacks in a global coupled model. Climate Dyn., 32, 1119-1138, https://doi.org/10.1007/s00382-008-0450-2.

Kushnir, Y., W. A. Robinson, I. Bladé, N. M. J. Hall, S. Peng, and R. Sutton, 2002: Atmospheric GCM response to extra- tropical SST anomalies: Synthesis and evaluation. J. Climate, 15, 2233-2256, https://doi.org/10.1175/1520-0442(2002)015<2233: AGRTES>2.0.CO;2.

Kwok, R., 2009: Outflow of Arctic Ocean sea ice into the Greenland and Barents Seas: 1979-2007. J. Climate, 22, 2438-2457, https://doi.org/10.1175/2008JCLI2819.1.

-, G. Spreen, and S. Pang, 2013: Arctic sea ice circulation and drift speed: Decadal trends and ocean currents. J. Geophys. Res. Oceans, 118, 2408-2425, https://doi.org/10.1002/jgrc.20191.

Liu, W. T., X. Xie, and P. P. Niiler, 2007: Ocean-atmosphere interaction over Agulhas Extension meanders. J. Climate, 20, 5784-5797, https://doi.org/10.1175/2007JCLI1732.1.

Macias Fauria, M., A. Grinsted, S. Helama, J. Moore, M. Timonen, T. Martma, E. Isaksson, and M. Eronen, 2010: Unprecedented low twentieth century winter sea ice extent in the western Nordic Seas since A.D. 1200. Climate Dyn., 34, 781-795, https://doi.org/10.1007/s00382-009-0610-z.

Maloney, E. D., and D. B. Chelton, 2006: An assessment of the sea surface temperature influence on surface wind stress in numerical weather prediction and climate models. J. Climate, 19, 2743-2762, https://doi.org/10.1175/JCLI3728.1.

Mantua, N. J., S. R. Hare, Y. Zhang, J. M. Wallace, and R. C. Francis, 1997: A Pacific interdecadal climate oscillation with impacts on salmon production. Bull. Amer. Meteor. Soc., 78, 1069-1080, https://doi.org/10.1175/1520-0477(1997)078<1069: APICOW $>2.0 . C O ; 2$.

Marshall, J., H. Johnson, and J. Goodman, 2001: A study of the interaction of the North Atlantic Oscillation with ocean circulation. J. Climate, 14, 1399-1421, https://doi.org/10.1175/ 1520-0442(2001)014<1399:ASOTIO>2.0.CO;2.

— J. Scott, and A. Proshutinsky, 2017: "Climate response functions" for the Arctic Ocean: A proposed coordinated modelling experiment. Geosci. Model Dev., 10, 2833-2848, https://doi.org/10.5194/gmd-10-2833-2017.

Marsland, S. J., H. Haak, J. H. Jungclaus, M. Latif, and F. Roske, 2003: The Max-Planck-Institute global ocean/sea ice model with orthogonal curvilinear coordinates. Ocean Modell., 5, 91-127, https://doi.org/10.1016/S1463-5003(02)00015-X.

Meneghello, G., J. Marshall, J.-M. Campin, E. Doddridge, and M.-L. Timmermans, 2018: The ice-ocean governor: Ice-ocean stress feedback limits Beaufort Gyre spin-up. Geophys. Res. Lett., 45, 11 293-11 299, https://doi.org/10.1029/2018GL080171.

Muilwijk, M., and Coauthors, 2019: Arctic Ocean response to Greenland Sea wind anomalies in a suite of model simulations. J. Geophys. Res. Oceans, 124, 6286-6322, https://doi.org/ 10.1029/2019JC015101.

Nakamura, M., 2013: Greenland sea surface temperature change and accompanying changes in the Northern Hemispheric climate. J. Climate, 26, 8576-8596, https://doi.org/10.1175/ JCLI-D-12-00435.1.

Nonaka, M., and S.-P. Xie, 2003: Covariations of sea surface temperature and wind over the Kuroshio and its extension: Evidence for ocean-to-atmosphere feedback. J. Climate, 16, 1404-1413, https://doi.org/10.1175/1520-0442(2003)16<1404: COSSTA $>2.0 . \mathrm{CO} ; 2$.

Notz, D., F. A. Haumann, H. Haak, J. H. Jungclaus, and J. Marotzke, 2013: Arctic sea-ice evolution as modeled by Max Planck Institute for Meteorology's Earth system model. J. Adv. Model. Earth Syst., 5, 173-194, https://doi.org/10.1002/jame.20016.

Okumura, Y., S.-P. Xie, A. Numaguti, and Y. Tanimoto, 2001: Tropical Atlantic air-sea interaction and its influence on the NAO. Geophys. Res. Lett., 28, 1507-1510, https://doi.org/ 10.1029/2000GL012565. 
O'Neill, L. W., D. B. Chelton, S. K. Esbensen, and F. J. Wentz, 2005: High-resolution satellite measurements of the atmospheric boundary layer response to SST variations along the Agulhas Return Current. J. Climate, 18, 2706-2723, https:// doi.org/10.1175/JCLI3415.1.

, S. K. Esbensen, N. Thum, R. M. Samelson, and D. B. Chelton, 2010: Dynamical analysis of the boundary layer and surface wind responses to mesoscale SST perturbations. J. Climate, 23, 559-581, https://doi.org/10.1175/2009JCLI2662.1.

- D. B. Chelton, and S. K. Esbensen, 2012: Covariability of surface wind and stress responses to sea surface temperature fronts. J. Climate, 25, 5916-5942, https://doi.org/10.1175/ JCLI-D-11-00230.1.

Park, K.-A., and P. C. Cornillon, 2002: Stability-induced modification of sea surface winds over Gulf Stream rings. Geophys. Res. Lett., 29, 2211, https://doi.org/10.1029/2001GL014236.

- —_ , and D. L. Codiga, 2006: Modification of surface winds near ocean fronts: Effects of Gulf Stream rings on scatterometer (QuikSCAT, NSCAT) wind observations. J. Geophys. Res., 111, C03021, https://doi.org/10.1029/2005JC003016.

Proshutinsky, A., R. Krishfield, and M.-L. Timmermans, 2020: Introduction to special collection on Arctic Ocean modeling and observational synthesis (FAMOS) 2: Beaufort Gyre phenomenon. J. Geophys. Res. Oceans, 125, e2019JC015400. https://doi.org/10.1029/2019JC015400.

Royer, J. F., S. Planton, and M. Déqué, 1990: A sensitivity experiment for the removal of Arctic sea ice with the French spectral general circulation model. Climate Dyn., 5, 1-17, https:// doi.org/10.1007/BF00195850.

Rudels, B., and D. Quadfasel, 1991: Convection and deep water formation in the Arctic Ocean-Greenland sea system. J. Mar. Syst., 2, 435-450, https://doi.org/10.1016/0924-7963(91)90045-V.

Saha, S., and Coauthors, 2010: The NCEP Climate Forecast System Reanalysis. Bull. Amer. Meteor. Soc., 91, 1015-1058, https:// doi.org/10.1175/2010BAMS3001.1.

Schlichtholz, P., 2013: Observational evidence for oceanic forcing of atmospheric variability in the Nordic seas area. J. Climate, 26, 2957-2975, https://doi.org/10.1175/JCLI-D-11-00594.1.

_ 2014: Local wintertime tropospheric response to oceanic heat anomalies in the Nordic seas area. J. Climate, 27, 8686-8706, https://doi.org/10.1175/JCLI-D-13-00763.1.

Screen, J. A., and I. Simmonds, 2010: The central role of diminishing sea ice in recent Arctic temperature amplification. Nature, 464, 1334-1337, https://doi.org/10.1038/nature09051.

Small, R. J., and Coauthors, 2008: Air-sea interaction over ocean fronts and eddies. Dyn. Atmos. Oceans, 45, 274-319, https:// doi.org/10.1016/j.dynatmoce.2008.01.001.

Smedsrud, L. H., and Coauthors, 2013: The role of the Barents Sea in the Arctic climate system. Rev. Geophys., 51, 415-449, https://doi.org/10.1002/rog.20017.
Song, Q., P. Cornillon, and T. Hara, 2006: Surface wind response to oceanic fronts. J. Geophys. Res., 111, C12006, https://doi.org/ 10.1029/2006JC003680.

_ D. B. Chelton, S. K. Esbensen, N. Thum, and L. W. O'Neill, 2009: Coupling between sea surface temperature and low-level winds in mesoscale numerical models. J. Climate, 22, 146-164, https://doi.org/10.1175/2008JCLI2488.1.

Sorteberg, A., N. G. Kvamst $\varnothing$, and Ø. Byrkjedal, 2005: Wintertime Nordic Seas cyclone variability and its impact on oceanic volume transports into the Nordic Seas. The Nordic Seas: An Integrated Perspective, Geophys. Monogr., Vol. 158, Amer. Geophys. Union, https://doi.org/10.1029/158GM10.

Stevens, B., and Coauthors, 2013: Atmospheric component of the MPI-M Earth system model: ECHAM6. J. Adv. Model. Earth Syst., 5, 146-172, https://doi.org/10.1002/jame.20015.

Thoma, M., R. Gerdes, R. J. Greatbatch, and H. Ding, 2015: Partially coupled spin-up of the MPI-ESM: Implementation and first results. Geosci. Model Dev., 8, 51-68, https://doi.org/ 10.5194/gmd-8-51-2015.

Tietsche, S., D. Notz, J. H. Jungclaus, and J. Marotzke, 2013: Predictability of large interannual Arctic sea-ice anomalies. Climate Dyn., 41, 2511-2526, https://doi.org/10.1007/ s00382-013-1698-8.

Vinje, T., 2001: Anomalies and trends of sea-ice extent and atmospheric circulation in the Nordic seas during the period 1864-1998. J. Climate, 14, 255-267, https://doi.org/10.1175/ 1520-0442(2001)014<0255:AATOSI $>2.0$. CO;2.

Visbeck, M., E. P. Chassignet, R. G. Curry, T. L. Delworth, R. R. Dickson, and G. Krahmann, 2003: The ocean's response to North Atlantic Oscillation variability. The North Atlantic Oscillation: Climatic Significance and Environmental Impact, Geophys. Monogr., Vol. 134, Amer. Geophys. Union, 113-145, https://doi.org/10.1029/134GM06.

Voet, G., D. Quadfasel, K. A. Mork, and H. Søiland, 2010: The mid-depth circulation of the Nordic Seas derived from profiling float observations. Dyn. Meteor. Oceanogr., 62, 516-529, https://doi.org/10.1111/j.1600-0870.2010.00444.x.

Wu, B., J. Wang, and J. Walsh, 2004: Possible feedback of winter sea ice in the Greenland and Barents Seas on the local atmosphere. Mon. Wea. Rev., 132, 1868-1876, https://doi.org/ 10.1175/1520-0493(2004)132<1868:PFOWSI $>2.0 . C O ; 2$.

Xie, S.-P., 2004: Satellite observations of cool ocean-atmosphere interaction. Bull. Amer. Meteor. Soc., 85, 195-208, https:// doi.org/10.1175/BAMS-85-2-195.

Xu, H., H. Tokinaga, and S.-P. Xie, 2010: Atmospheric effects of the Kuroshio large meander during 2004-05. J. Climate, 23 4704-4715, https://doi.org/10.1175/2010JCLI3267.1.

_ M. Xu, S.-P. Xie, and Y. Wang, 2011: Deep atmospheric response to the spring Kuroshio over the East China Sea. J. Climate, 24, 4959-4972, https://doi.org/10.1175/JCLI-D-10-05034.1. 